\title{
Manifestaciones reumatológicas en pacientes infectados con virus de la inmunodeficiencia humana
}

\author{
Rheumatic manifestations in patients with HIV \\ infection
}

\author{
Kelly Patricia Vega • Bogotá, D.C.
}

\section{Resumen}

La infección por virus de la inmunodeficiencia humana adquirida se ha convertido en una pandemia mundial, en Colombia la prevalencia en 2008 fue de $0.6 \%$ a $0.8 \%$.

Los últimos 21 años desde que conocemos la infección se han visto inicialmente las manifestaciones reumatológicas de la inmunodeficiencia, y con los avances en materia de terapia antirretroviral en la actualidad dichas manifestaciones están más en relación con el tratamiento.

Se realizó búsqueda de literatura empleando términos MesH en Pubmed encontrando 131 artículos de los cuales se incluyeron 26 que cumplían con los objetivos del tema.

La infección VIH y el SIDA presentan una gran variedad de manifestaciones reumatológicas, que incluso pueden ser el debut de la infección.

Las espondiloartropatías son la expresión reumatológica más frecuente.

El inicio de la terapia antirretroviral de alta eficiencia en 1996, partió en dos la evolución de la infección por virus de la inmunodeficiencia humana, y las manifestaciones reumatológicas asociadas a ésta (Acta Med Colomb 2010; 1: 15-20).

Palabras clave: VIH, artritis, espondiloartropatías, terapia antirretroviral.

\section{Abstract}

Infection with human acquired immunodeficiency virus has become a global pandemic, the prevalence in Colombia in 2008 was $0.6 \%$ to $0.8 \%$.

During the past 21 years, since the infection became widely known, rheumatic manifestations of immune deficiency have been detected. The advancement of antiretroviral therapy has shown that these manifestations are more related to the treatment than to the infection itself.

A search of the literature was conducted using MeSH terms in Pub med. One hundred and thirty one eligible articles were found.

HIV infection and AIDS have a variety of rheumatologic manifestations, which may even be the debut of the infection.

The spondyloarthropathies are the most common rheumatologic expression.

The initiation of high-efficiency antiretroviral therapy in 1996 was a major breakthrough in the evolution of HIV-infection and associated rheumatic manifestations (Acta Med Colomb 2010; 1: 15-20).

Keywords: HIV, arthritis, spondyloarthropathies, antiretroviral therapy.

\author{
Dra. Kelly Patricia Vega Castro: Médico \\ General Universidad Nacional de Colom- \\ bia, Residente de Medicina Interna Uni- \\ versidad Militar Nueva Granada, Hospital \\ Militar Central. Bogotá, D.C. \\ Instituciones Afiliadas: Hospital Militar \\ Central, Servicio de Medicina Interna. Uni- \\ versidad Militar Nueva Granada, Facultad \\ de Medicina. \\ Presentación en congresos: No \\ Patrocinio financiero: No aplica \\ Correspondencia. Dra. Kelly Patricia Vega \\ Castro, Carrera 69I No 66-34 Bogotá; D.C. \\ Colombia. Tel: 3117721-Cel: 3005543970 \\ E-mail: kellypat74@gmail.com \\ kellypat74@hotmail.com \\ Recibido: 14/V/09 Aceptado: 28/I/10
}

\section{Introducción}

La prevalencia mundial, de infección con el virus de la inmunodeficiencia humana (VIH) está calculada en 40.3 millones de personas. En Colombia no se tienen datos precisos pero según el reporte de la Organización Mundial de la Salud en 2008, la prevalencia en Colombia fue de $0.6 \%$ y $0.8 \%$ (1).

La infección por VIH se considera como la pandemia de las ultimas dos décadas, y la evolución de la enfermedad, en principio sin tratamiento permitió que estos pacientes 
desarrollaran toda suerte de complicaciones de tipo principalmente infeccioso, algunas de las cuales tenían relación directa con el aparato osteoarticular.

A partir de la aparición de la terapia antirretroviral de alta eficiencia, la historia de la infección se parte en dos, ya que estos pacientes han alcanzado expectativas de vida iguales a las de sujetos no infectados.

La vida de los pacientes con infección por VIH se ha prolongado de tal forma que las comorbilidades que los afectan son también distintas; de tal suerte que las enfermedades infecciosas, han reducido su importancia, y las enfermedades crónicas han tomado la batuta de las complicaciones de estos pacientes.

El diseño y diligenciamiento de bases de datos completas permitirán en el futuro la toma de decisiones en salud que sean costo efectivas para estos pacientes.

\section{Metodología}

Se realizó una búsqueda bibliográfica en los últimos 15 años en Pubmed, empleando términos MesH, para responder a la pregunta que generó la monografía ¿Cuáles son las manifestaciones reumatológicas de los pacientes con infección VIH? obteniendo un total de 131 artículos de los cuales se revisaron 26, que cumplían con el objeto de la monografía.

\section{Manifestaciones reumatológicas de los pacientes con infección por VIH}

Los pacientes con infección por VIH presentan manifestaciones reumatológicas que están determinadas por la infección misma, su evolución en el tiempo, y la administración de tratamiento. Las manifestaciones reumatológicas, pueden dividirse en cuatro grandes grupos (2) (Figura 1).

\section{Derivadas de la infección VIH per se}

Espondiloartropatías, artralgia, artritis, mialgia/fibromialgia, condiciones misceláneas, síndrome de infiltración linfocítica difusa (DILS), presencia de anticuerpos sin manifestaciones clínicas de autoinmunidad.

\section{Presentadas por estado de inmunosupresión}

Artritis séptica, osteomielitis, polimiositis, infección de tejidos blandos.

\section{Secundarias a la terapia antirretroviral de alta eficiencia}

Miopatía, osteonecrosis, gota, hombro congelado, disfunción de la articulación temporomandibular (ATM), tendinitis (A partir de 1996).

\section{Comportamientos paradójicos de enfermedades crónicas autoinmunes con la infección VIH}

Lupus eritematoso sistémico, artritis reumatoide, vasculitis.

\section{Biología de la infección por el VIH}

La exposición al VIH, que es un retrovirus, y hace parte de los lentivirus, puede presentarse por transfusión, contacto sexual, accidente biológico o vía vertical.

El virus en sangre interactúa a través de su glicoproteína G120, con el receptor CD4 y el correceptor CCR5 de acción indispensable, para permitir el ingreso del virus a los linfocitos T CD4, macrófagos y células microgliales.

La unión glicoproteína con CD4 y el correceptor induce clivaje de proteínas del virus, ingreso del virus en el citoplasma para la formación del complejo de transcripción reversa que produce cadenas de DNA viral y proteínas derivadas del virus como $\mathrm{P} 17$, integrasa y proteína viral $\mathrm{R}$.

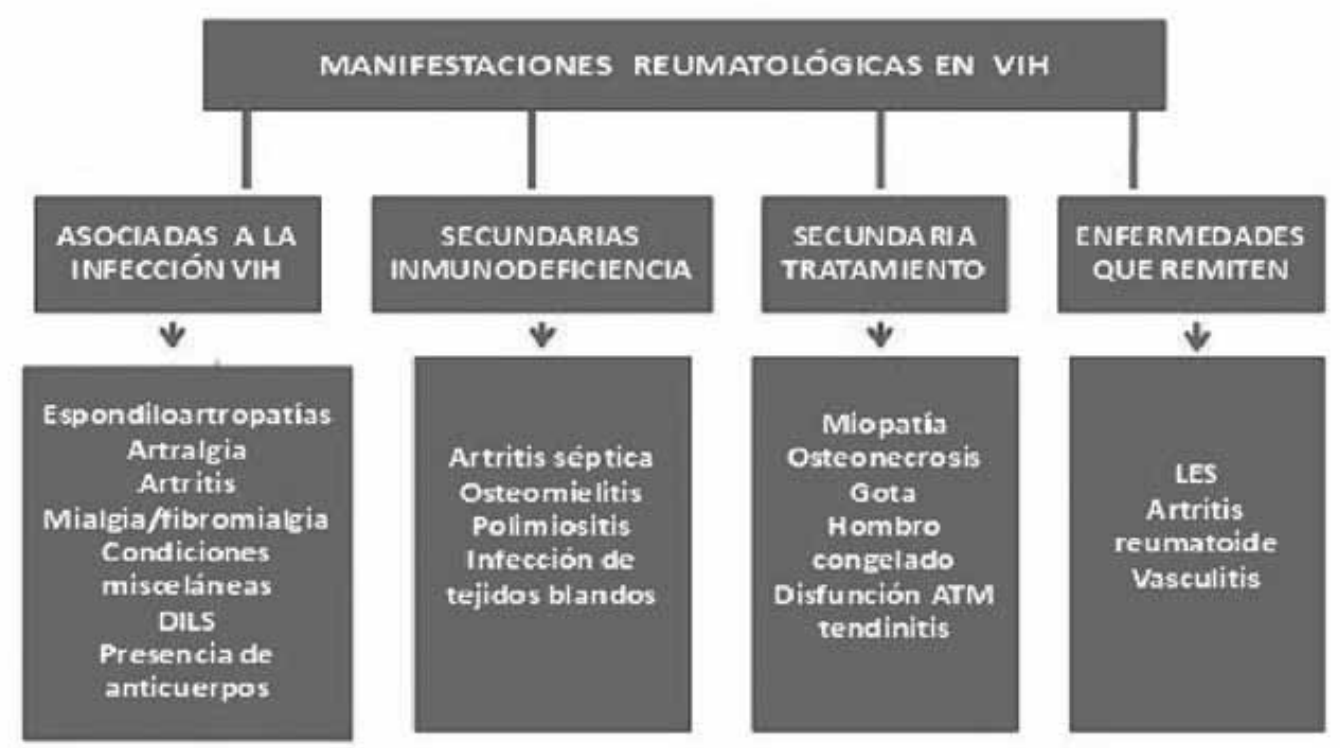

Figura 1. Modelo de clasificación de las manifestaciones reumatológicas de paciente con infección VIH. 
La traslocación al núcleo de estos productos y la integración con el DNA celular, provoca modificaciones irreversibles en el linfocito que activa y migra al ganglio linfático donde produce activación del sistema inmune, con producción de citocinas y anticuerpos que intentan la neutralización del virus $(3,4)$.

\section{Patogénésis}

La explicación de los fenómenos que llevan a las manifestaciones reumáticas y/o autoinmunes en pacientes con infección VIH, se ha estudiado ampliamente, proponiendo dos mecanismos: indirecto y directo.

\section{Indirecto}

- Sobreestimulación de la respuesta humoral. Hiperglobulinemía, linfocitos B estimulados en forma permanente por desequilibrio de sistema inmune con mayor conversión a células plasmáticas productoras de anticuerpos.

- Formación de complejos inmunes. Antígeno-anticuerpo, que pueden depositarse en sistema articular, ocasionando dolor y retroalimentación positiva para perpetuación de la respuesta inmune.

- Mimetismo molecular. Respuesta inmune que se desencadena por un péptido de origen bacteriano o viral que tiene secuencias muy similares, con proteínas estructurales, de los tejidos. De forma que los anticuerpos pueden reconocer con la misma avidez que a los péptidos antigénicos originales.

La respuesta inmune $\mathrm{TH} 2$ esta muy activa con expansión clonal de linfocitos B, que puede generar anticuerpos. Por otro lado, respuesta TH1 depletada genera fosforilación proteínas, clivaje de mieloperoxidasas, y del C3b que perpetua el estado inflamatorio de los desordenes reumáticos y la propensión a desarrollar enfermedades generada por gérmenes intracelulares (4).

\section{Directo}

El virus de inmunodeficiencia humana tiene tropismo por los linfocitos CD4, pero también por macrófagos. La interacción virus macrófago explica los aislamientos del virus, que se han hecho en tejido sinovial, ya que los sinoviocitos tipo A son similares a los macrófagos y su unión con un patógeno genera presentación local del antígeno con migración articular de las células inflamatorias.

Sin embargo estos procesos son dependientes de condiciones de base de los pacientes, como HLA B27, historia familiar, infecciones concomitantes (5).

\section{Anormalidades de laboratorio}

La presencia de factor reumatoide, anticuerpos antinucleares y crioaglutininas, se puede encontrar en $84 \%$, sin revestir importancia por cuanto no están en relación con datos clínicos de enfermedad reumática y/o autoinmune.
Estas anormalidades son secundarias a hiperactividad de la función de células B, dado que existe imbalance entre linfocitos B y T.

Dichos hallazgos disminuyen en forma dramática con la terapia antirretroviral.

\section{Síndromes clínicos: por infección VIH Artralgia asociada a VIH adquirida}

Tiene prevalencia entre $5 \%$ y $45 \%$ dependiendo de las series. Presentación oligoarticular, principalmente afectando rodillas, hombros y codos, autolimitada, no mayor a 24 horas, cede con tratamiento analgésico, es una manifestación inespecífica, constituyendo el llamado síndrome articular doloroso intermitente; por otro lado su presencia hace parte de las manifestaciones del síndrome de infección aguda por VIH en $28 \%$ a $45 \%$ de los casos (6).

\section{Espondiloartropatías}

Son las enfermedades reumáticas más frecuentemente asociadas a infección VIH, aunque existen diferencias geográficas que tiene que ver principalmente con la raza, y la presencia de HLA B27. En este grupo las más frecuentes son la artritis reactiva y la artritis psoriásica (7).

Sin embargo, la clasificación de las espondiloartropatías por los criterios diagnósticos habituales es difícil en los pacientes con infección VIH, particularmente al aplicar los criterios de Amor's. Por ende se deben estandarizar criterios para la clasificación y diagnóstico en este grupo de pacientes $(8)$.

\section{Artritis psoriásica}

El primer caso de asociación de VIH y psoriasis fue descrito en 1987 con aparición tardía en la evolución de la infección por $\mathrm{VIH}$, en pacientes con conteos de CD4 por debajo de 400 por $\mathrm{ml}$, en principio se pensaba que sólo aparecía subsecuente a infección por microorganismos, principalmente con Pneumocistis pneumonia (11).

La presentación clínica es con compromiso poliarticular, ungueal, entesopatía y dactilitis; y la forma vulgaris corresponde con $(78 \%)$, inversa $(37 \%)$, guttata (29\%). En general los pacientes tienen buena respuesta a tratamiento con agentes con efecto antifactor de necrosis tumoral, metrotexate, pero sobre todo con la instauración de la terapia antirretroviral (22).

La prevalencia de psoriasis y artritis psoriásica oscila entre $10 \%$ y $12 \%$ en los pacientes con infección VIH (2).

La depresión del sistema inmune principalmente en lo referente a la respuesta $\mathrm{TH} 1$, ocasiona generalización de la psoriasis cutánea y empeoramiento de las manifestaciones articulares (6).

\section{Artritis reactiva: síndrome de Reiter}

Presentación como oligoartritis asimétrica predominante en miembros inferiores, asociada a entesitis, fascitis plantar, que son los datos clínicos que se permiten dife- 
renciarla de artritis reumatoide; además de la presencia frecuente de Queratoderma blenorragicum, balanitis circinada, $e$ historia de disentería, causada por shiguella, salmonella, amebas, y/o por enfermedades de transmisión sexual principalmente por Clamydia trachomatis, Neisseria gonorrea entre otros.

El HLA B-27 se encuentra en $80 \%$ de los caucásicos, pero ausente en la población africana donde la prevalencia e incidencia de infección VIH es mas alta(8) Buena respuesta a tratamiento con Sulfasalazina, Metrotexate, Hidroxicloroquina (6).

\section{Artritis gotosa}

La prevalencia de la gota es de alrededor de $0,5 \%$, y la de hiperuricemia es muy alta y varía dependiendo de la serie entre $35 \%$ y $45 \%$.

La replicación viral genera un alto recambio celular que incrementan niveles de uratos, igualmente la terapia antirretroviral principalmente con didanosina y estavudina, las cuales pueden generar lesión mitocondrial con incremento en la producción de lactato, lo que a su vez estimula reabsorción de uratos en el túbulo proximal: la depleción de adenosina trifosfato secundaria, induce síntesis de uratos en el ciclo de las purinas.

El tratamiento consiste en la administración de antiinflamatorios no esteroideos orales, y alopurinol $(6,7)$.

\section{Síndrome de linfocitosis infiltrativa difusa}

Se presenta en alrededor del 3\% de los pacientes con infección VIH, más comúnmente después de varios años de la seroconversión

Consiste en linfocitosis T CD8 periférica, e infiltración por anticuerpos contra CD8 en tejidos de múltiples órganos. Lo que está en relación con una fuerte respuesta inmune del hospedero.

El paciente con crecimiento parotídeo, síntomas de síndrome Sicca y en algunos casos parálisis facial, derivada de la compresión del séptimo par craneano a su paso por la parótida que se encuentra edematizada.

Es frecuentemente asociado a HLA DRB-1, e infección por CMV. Anti-LA y anti-RO son negativos; responden en forma favorable al tratamiento antirretroviral, pilocarpina, esteroides.

La administración de dosis altas de ritonavir puede generar infiltración lipomatosa de la parótida, que puede llegar a ser indistinguible del síndrome de linfocitosis infiltrativa difusa.

\section{Manifestaciones por inmunodeficiencia}

Las infecciones articulares, piel, tejidos blandos, y óseas, en general obedecen al mismo patrón de microorganismos de la población no infectada; sin embargo, dependiendo de las condiciones particulares del paciente. Día tras día son menos frecuentes por la terapia antirretroviral conjugada de alta eficiencia. Existe mayor riesgo entre los pacientes en hemodiálisis, diálisis peritoneal, quimioterapias, y en otros casos abuso de drogas endovenosas.

En inmunosupresión severa, se pueden presentar infecciones articulares por micobacterias tuberculosas, y no tuberculosas, gérmenes no usuales, hongos y parásitos, entre otros.

Entre ellas se encuentran la artritis séptica cuyo tratamiento sigue siendo el drenaje articular urgente, y el tratamiento antibiótico, abscesos musculares y de tejidos blandos, miositis infecciosas, y en algunos pacientes osteomielitis (13).

\section{La terapia antirretroviral conjugada de alta eficiencia, como factor de riesgo para complicaciones osteoarticulares.}

El cambio radical, en la expectativa y sobre todo en la calidad de vida de los pacientes es evidente después de mediados de la década de los 90 , los progresos en la calidad y características de las moléculas, han permitido el mayor conocimiento de sus efectos secundarios, dentro de los que sobresalen los relacionados con manifestaciones articulares, tendinitis, y en algunos casos osteonecrosis. Aunque los más precozmente reconocidos son los que tienen que ver con osteopenia y desmineralización ósea, que dependen directamente de factores del hospedero y del mismo VIH (14).

Los más frecuentes. y reconocidos son los relacionados con indinavir y zidovudina.

\section{Indinavir}

Antirretroviral cuyo efecto farmacológico es la inhibición de la proteasa del virus. Se ha visto relacionado con:

Osteoporosis. En relación con el factor de necrosis tumoral alfa y la interleucina 1; cambios en el metabolismo del 1,25 hidroxicolecalciferol.

Osteonecrosis. Principalmente en paciente con dislipidemia, y en quienes usan esteroides de forma crónica, trombosis interósea, y de la vasa vasorum.

Síndrome túnel del carpo. Depósito de materiales que comprimen retináculo flexor con dolor.

Hombro congelado. Depósito de lípidos, en manguito de los rotadores, con calcificación del mismo (14).

\section{Zidovudina}

Ampliamente relacionada con miopatía que se caracteriza por la presencia de mialgia insidiosa, elevación de creatina quinasa.

La patogénesis es por compromiso que lleva disfunción cadena transportadora de electrones mitocondrial y en casos severos puede presentarse rabdomiolisis y falla renal por pigmentos.

El inicio de la terapia antirretroviral supone un compromiso por parte de médico y paciente en la detección de efectos secundarios, y signos que alerten acerca de los mismos para evitar la progresión de los síntomas (15). 


\section{¿Qué hay de la actividad de enfermedades con trasfondo autoinmune como la artritis reumatoide y el lupus eritematoso sistémico, durante la evolución de la infección VIH?}

La interacción VIH con sistema inmune sucede de forma gradual en el tiempo, y por esto las enfermedades autoinmunes presentan un comportamiento bimodal.

Durante la infección el desempeño del sistema inmune es comparable con el de un sujeto sano; por lo que la actividad de la artritis y del lupus permanece presente. En la medida que el virus avanza y se presenta seroconversión la competencia inmunológica del paciente disminuye, y la actividad de las enfermedades autoinmunes crónicas tiende a disminuir; en algunos casos resuelve de forma a completa. Hasta este punto llegaban la mayor parte de pacientes hasta antes de 1995, posterior a este año, con el inicio de tratamiento altamente eficiente ocurre reactivación de cuadro mediados por autoinmunidad por la aparición de Síndrome de Reconstitución Inmunológica, que está marcado por ascenso de la cifra de linfocitos T CD4 y descenso de la carga viral $(15,17)$.

Durante la fase de infección, conversión e inmunosupresión, se han realizado estudios con ciclosporina, un agente inmunosupresor usado en pacientes receptores de trasplantes, asociado a hidroxicloroquina encontrando que podría ser efectivo, para mantener la respuesta a la terapia antirretroviral a largo plazo, por la inhibición de la replicación viral y la modulación del sistema inmune, siempre que se administre en dosis bajas (16).

El hallazgo de autoanticuerpos puede ocurrir en general en títulos bajos, es bastante frecuente la detección de anticuerpos anticardiolipinas en pacientes con SIDA avanzado, pero éstos rara vez tienen significancia clínica, pero pueden ser coadyuvantes del efecto protrombótico de los pacientes con VIH.

Los ANCA pueden estar presentes, pero sin asociación con vasculitis no revierten ninguna significancia (17).

\section{Vasculitis}

Gherardi encontró en biopsias de músculo, nervio y piel de 34 pacientes con infección con VIH, inflamación vascular que según los criterios del Colegio Americano de Reumatología cuatro de ellos cumplían criterios de Panarteritis Nodosa; uno de púrpura de Henoch Shonlein y seis de vasculitis inducida por drogas, los demás tenían inflamación vascular inespecífica.

Se documentó además la presencia de crioglobulinas tipo II y III, $27 \%$ de los pacientes con infección únicamente con VIH pero esta cifra se puede doblar en pacientes coinfectados con virus de la hepatitis $\mathrm{C}$, la terapia antirretroviral y el interferón disminuyen la crioglobulinemia.

Entre las vasculitis de mediano vaso la más frecuente es la poliarteritis nodosa, y de las de gran vaso las de origen infeccioso y leucocitoclástica, la aparición de eventos isquémicos cardiacos y cerebrales que son manifestaciones de los extremos de la enfermedad con recuentos de CD4 mayores de 500, o menores de 200.

La administración de tratamiento antirretroviral en caso de recuentos bajos, o de la causa infecciosa cuando los recuentos son adecuados, como son las terapias de elección (6).

\section{Simulación}

La infección VIH puede camuflarse bajo los síntomas de enfermedad reumática, por lo que la consideración de síntomas de predominio muscular, articular, sin factores de riesgo conocidos para enfermedad reumática articular, pero con conductas de riesgo para infección VIH debe dirigirse a descartar infección.

Como siempre los factores de hospedero y su interacción con el medio ambiente son determinantes importantes de la intensidad y el desarrollo de las manifestaciones (18).

Ha surgido interés en el comportamiento de estos pacientes con la administración de medicamentos con efecto antifactor de necrosis tumoral alfa, en aquellos casos en los que la enfermedad reumatológica es refractaria a los tratamientos previos, en un reporte de ocho casos realizado por expertos de la Universidad de Texas, sugirió que esta terapia puede ser empleada en pacientes con refractariedad de la comorbilidad reumatológica, pero con infección VIH no avanzada (20).

En nuestro país los registros no son llevados en forma adecuada por lo que carecemos de datos propios. De igual manera en el Hospital Militar Central es necesario la construcción de la base de datos de paciente con infección VIH, para la descripción de las características de nuestra población que ha sido blanco de infección y posterior a esto la determinación de la prevalencia de manifestaciones reumatológicas en Colombia.

\section{Conclusiones}

La infección VIH y el SIDA presentan una gran variedad de manifestaciones reumatológicas, que incluso pueden ser el debut de la infección.

Las espondiloartropatías son las formas más frecuentes y dentro de ellas la artritis reactiva y la psoriásica.

El olfato clínico debe hacernos pensar en la posibilidad de infección VIH en todo paciente con síntomas y/o síndromes reumatológicos que no tenga otros datos al interrogatorio de cronicidad o para pensar en enfermedad de tejido conectivo.

La historia de los pacientes con VIH está dividida en dos después de inicio de la terapia antirretroviral de alta eficiencia en 1996.

La terapia antirretroviral conjugada de alta eficiencia ha permitido igualar la expectativa de vida de los pacientes con $\mathrm{VIH}$, con la de sujetos no infectado, y de forma secundaria han aparecido enfermedades crónicas que desconocíamos antes en este grupo de paciente.

Es paradójico el efecto de la infección VIH en enfermedades autoinmunes, como artritis reumatoide y lupus eritematoso. 
El campo de acción para el conocimiento de nuestra población, patrones de presentación, y características sociodemográficas de nuestros pacientes es absolutamente extenso.

La conciencia por el personal de salud de la importancia de los registros y de las bases de datos en fundamental para lograr políticas de salud que sean realmente costoefectivas.

\section{Referencias}

1. Epidemiological Fact Sheet on HIV and AIDS. Update WHO 2008. Core data on epidemiology and response. Página Web. Organización Mundial de la Salud. www.who.int/en. Acceso febrero de 2009.

2. Louthrenoo W. Rheumatic manifestations of human immunodeficiency virus infection. Curr Opin Rheumatol 2008; 20: 92-9.

3. Mandell, Douglass, Benett. Principles and practice and infection disease. Sixth edition. 2006. Chapter 166: pg 1685-1705

4. Mody GM, Parke FA, Reveille JD. Articular manifestations of human immunodeficiency virus infection. Best Pract Res Clin Rheumato 2003; 17: 265-87.

5. Albert LJ, Inman RD. Molecular mimicry and Autoimmunityn. $N$ Engl J Med 1999; 341: 2068-74.

6. Walker $\mathbf{U}$, Tyndall T, Daikeler T. Rheumatic conditions in human immunodeficiency virus infection. Rheumatology 2008; 47: 952-9.

7. Reveille JD. Changing Spectrum of HIV and Rheumatic Disease. Seminar Arthritis Rheum 2000; 30: 147-66.

8. Gisele Z; Goddard A; Yehuda S. HIV and Autoimmunity. Infection and Autoimmunity 2004; 171-9.

9. Medina F, Perez L; Moreno J. Rheumatic Manifestations of Human Immunodeficiency Virus Infection. Infect Dis Clin N Am 2006; 20: 891-912.

10. Ntsiba H., LaminiIs N. Inflammatory Joint Disease in HIV-infected patients. a form of spondylo-arthropathy?. Revue du Rhumatisme 2004; 71: 584-7.

11. Dalgleish Angus G, Weiss Robin. HIV and the new viruses. Michigan. Segunda Edición. 1999. Capitulo 8, paginas 115 -131
12. Duvic M, Johnson TM, Rapini RP, Freese T, Brewton G, Rios A. Acquired immunodeficiency syndrome-associated psoriasis and Reiter's syndrome. Arch Dermatol 1987; 123: 1622-32.

13. Weitzul S; Duvic M. HIV-Related Psoriasis and Reiter's Syndrome. Semin Cutan Med Surg 1997; 16: 213-8.

14. Reveille JD, Williams FM. Infection and musculoskeletal conditions: Rheumatologic complications of HIV infection. Best Pract Res Clin Rheumatol 2006; 20: $1159-79$.

15. Florence E, Schrooten E, Verdonck K. Rheumatological complications associated with the use of indinavir and other protease inhibitors. Ann Rheum Dis 2002; 61: $82-4$.

16. Lima AL,Zumiotti AV, Camanho JL, Benega ES, dos Santos AL, D'Elia CO, et al. Osteoarticular Complications Related to HIV Infection and Highly Active Antiretroviral Therapy. Braz Infect Dis; 2007:426-9.17.

17. Morrison E, Mcgilljohn Pe. Viral infections: Arthritis in the human immunodeficiency virus (HIV) infected patient. Baillieres Clin Rheumatol 1995 Feb; 9: $133-44$

18. Galeazzi M, Giannitti Ch, Manganelli S, Benucci M, Scarpatoc S, Bazzani Ch. Treatment of rheumatic diseases in patients with HCV and HIV infection. Autoimmun Rev 2008; 8: 100-3.

19. J. D. Reveille and F. M. Williams. Rheumatologic complications of HIV infection. Best Pract Res Clin Rheumatol 2006; 20: 1159 - 79

20. Navarro G, Villarreal M, Esquivel J; Delgado G, Garza M. Manifestaciones reumatológicas en pacientes con infección por virus de la inmunodeficiencia humana. Rev Mex Reumat 2001; 16: 381-94.

21. Cepeda EJ, Williams FM, Ishimori ML, Weisman MH, Reveille JD. The use of anti-tumour necrosis factor therapy in HIV-positive individuals with rheumatic disease. Ann Rheum Dis 2008; 67: 710-2.

22. Azeroual A, Harmouche H, Benjilali L, Mezalek ZT, Adnaoui M, Aouni M, et al. Rheumatoid arthritis associated to HIV infection. Eur J Intern Med 2008; 19: $34-5$.

23. D McGonagle, S Reade, H Marzo-Ortega,W Gibbon,PO'Connor,A Morgan, R Melsom, et al. Human immunodeficiency virus associated spondyloarthropathy: pathogenic insights based on imaging findings and response to highly active antiretroviral treatment. Ann Rheum Dis; 60: 696-8. 